Tomohiko Aoe MD, Tetsuo Kohchi MD, Tadanobu Mizuguchi MD

\title{
Respiratory induc- tance plethysmography and pulse oximetry in the assessment of upper airway patency in a child with Goldenhar's syndrome
}

\begin{abstract}
The anaesthetic management of a child with Goldenhar's syndrome and upper airway dysmorphology is presented. She had a history of severe dyspnoea due to deterioration of cor pulmonale caused by upper airway obstruction. The patency of the upper airway and oxygenation were evaluated during the perioperative period with respiratory inductive plethysmography (RIP) and pulse oximetry, which did not show severe upper airway abstruction or oxygen saturation below 80 per cent. Tracheal intubation was performed under inhalational anaesthesia with spontaneous breathing. This case suggests that RIP and pulse oximetry may be useful monitoring devices in the anaesthetic management of patients with upper ainvay problems as in Goldenhar's syndrome.
\end{abstract}

Nous décrivons l'anesthésie d'une enfant etteinte d'un syndrome de Goldenhar avec dysmorphie des voies respiratoires supérieures, dont l'obstruction avait amenée une dyspnée importante avec défaillance ventriculaire droite. En utilisant un pléthysmographe à inductance respiratoire et un oxymètre de pouls, nous avons pu déterminer avant l'intervention, que

\section{Key words}

AIRWAY: obstruction;

ANAESTHESIA: paediatric;

MONITORING: oxygen, pulse oximetry;

SYNDROME: Goldenhar's;

VENTILATION: measurement, inductive

plethysmography.

From the Department of Anesthesiology, School of Medicine, Chiba University, 1-8-1 Inohanacho, Chiba 280, Japan.

Address correspondence to: Dr. T. Aoc, Department of Anesthesiology, Chiba Cancer Center Hospital, 666-2 Nitonacho, Chiba 280, Japan. l'obstruction n'était pas sévère et que la saturation artérielle en oxygène se maintenait au dessus de 80 pour cent. Nous avons pu intuber la trachée de l'enfant après une induction par anesthésiques inhalés en ventilation spontanée. Cette technique et les moniteurs utilisés peuvent ainsi être utiles dans des cas d'obstruction haute des voies respiratoires.

Abnormalities of the upper airway make visualization of the larynx and tracheal intubation difficult. Also, maintenance of upper airway patency during induction of anaesthesia with a face mask is threatened because patients with upper airway dysmorphology frequently develop obstruction during sleep and anaesthesia. ${ }^{1}$

Goldenhar's syndrome, oculo-auriculo-vertebral dysplasia, is one of the congenital hemicraniofacial dysmorphologies characterized by epibulbar dermoids, auricular appendices and vertebral anomalies. ${ }^{2.3}$ The successful anaesthetic management of a child with this syndrome is reported and the use of respiratory inductive plethysmography (RIP) and pulse oximetry is suggested to assess airway patency and oxygenation during the perianaesthetic period.

\section{Case report}

A four-year-old, $16.5 \mathrm{~kg}$ female was scheduled for removal of a left epibulbar dermoid. She exhibited the characteristic manifestations of Goldenhar's syndrome; bird-like face, preauricular skin tags, high-arched palate, micrognathia and right-sided mandibular hypoplasia. Congenital heart disease and vertebral abnormalities were not seen.

She had a past history related to upper airway obstruction. At one month of age she suffered several aspirations during sucking, which caused pneumonias, and was fed by nasogastric tube for six months. She had no problems 
in the digestive tract. At 18 months, she experienced severe dyspnoea following upper airway infection. On arrival at the hospital, tracheal intubation facilitated by IV succinylcholine was performed by a paediatrician. But several attempts were required and a brief period of cardiac arrest occurred during the manoeuvre. Echocardiography, ECG and chest $x$-ray revealed right ventricular over-load and the dyspnoea was considered to be due to deterioration of the cor pulmonale caused by upper airway obstruction. After this episode medical treatment including digitalis was initiated and her right ventricular function improved.

Following these events, difficulties were anticipated in airway management during mask induction of anaesthesia, visualization of larynx, and tracheal intubation. Thus, on the night before the operation, the patency of the upper airway was evaluated during sleep with RIP and pulse oximetry. The RIP recorded central apnoea of over $12 \mathrm{sec}$ seven times during three hours and mild upper airway obstruction when snoring. However, severe upper airway obstruction and oxygen saturation below 80 per cent were not seen.

Upon induction of anaesthesia, precordial stethoscope, ECG, blood pressure cuff, RIP and pulse oximetry were applied to the patient. A jet ventilator was also prepared for use in case of difficult airway management. Atropine $0.3 \mathrm{mg}$ was given IV. Anaesthesia was induced slowly with halothane and nitrous oxide in 50 per cent oxygen and then the halothane inspired concentration was increased to 2.5 per cent in 100 per cent oxygen via a face mask with spontaneous ventilation. Paradoxical movements of the rib cage and abdomen, which implied upper airway obstruction, were not detected either visually or from RIP. After achieving an adequate level of anaesthesia, direct laryngoscopy allowed visualization of the epiglottis but not the glottis, and tracheal intubation was performed. Anaesthesia was maintained with halothane and nitrous oxide in 50 per cent oxygen with manual ventilation. Neuromuscular blocking agents were not used. The anaesthetic course was uneventful and extubation was performed when the patient was alert and moving vigorously. Upper airway patency was maintained following extubation.

\section{Discussion}

In the anaesthetic management of a patient with Goldenhar's syndrome, anaesthetists should be aware that congenital heart disease $e^{4.5}$ and vertebral anomalies are possible complications of this syndrome. Although this patient did not have these complications, she had had an episode of right heart failure due to cor pulmonale, and was receiving medical treatment.
Craniofacial anomalies such as micrognathia, glossoptosis and relative macroglossia often cause mechanical airway obstruction, especially during sleep. These anatomical abnormalities in upper airway structure are considered to be responsible for the occurrence of obstructive sleep apnoea. ${ }^{6-8}$ Physiologically, during nonrapid-eye-movement-sleep upper airway muscle tone is reduced. A decrease in FRC during sleep is also considered to reduce the pharyngeal area. These changes during sleep lead to an increase in upper airway resistance. ${ }^{9.10}$ Anatomical anomalies of the upper airway further increase upper airway resistance, which may, in turn, increase the risk of upper airway obstruction. Right heart failure is a common complication of the obstructive sleep apnoea syndrome. " Sustained hypoxaemia and/or hypercapnia over a 24-hr period due to airway obstruction are considered to be responsible for the development of right heart failure by their effects on the pulmonary vasculature. ${ }^{12}$ Similar mechanisms might have played a role in the genesis of right heart failure in our patient.

It has shown, in the cat ${ }^{13}$ and in humans, ${ }^{14}$ that deepening anaesthesia progressively depresses the swallowing reflex. Furthermore, hypoglossal nerve activity has been shown to be more sensitive to anaesthesia than the phrenic nerve. ${ }^{15,16}$ Hence, during induction of anaesthesia with inhalational agents, upper airway obstruction may develop in association with a decrease in upper airway muscle tone as during sleep. This effect of anaesthesia would be more pronounced in a patient with upper airway dysmorphology as an effect of sleep. Thus, prior to anaesthesia the patient's respiratory pattern and arterial oxygen saturation during sleep were monitored with RIP and pulse oximetry. RIP is a non-invasive respiratory monitoring device and can be easily applied to a child. ${ }^{17}$ Changes in the cross-sectional area of the rib cage and abdomen arising from respiratory movements are detected through alterations of the self-inductance of two coils placed around the rib cage and abdomen. The sum of these changes reflects tidal volume qualitatively, or semi-quantitatively, through appropriate calibration procedure with spirometry. Analogue wave forms of rib cage and abdominal excursions and their sum (tidal volume) can be seen on a video monitor in real time. During central apnoea all respiratory efforts cease and there are negligible rib cage, abdominal, and tidal volume waves. During obstructive apnoea there is a negligible tidal volume wave with paradoxical movements of the rib cage and abdomen. We measured tidal volume with the qualitative diagnostic calibration procedure ${ }^{18}$ and observed the breathing pattern. Although mild upper airway obstruction and several central apnoeic episodes were observed in this patient during sleep, these were 
considered to be within the physiological range. ${ }^{19}$ Hence, it was expected that the induction of anaesthesia with halothane could be achieved with the maintenance of a patent airway.

In the anaesthetic management of children with abnormal upper airway geometry, an inhalational induction of anaesthesia allowing spontaneous breathing is generally recommended. ' In children the small functional residual capacity causes rapid and profound development of hypoxia during apnoea. Early detection of ventilatory disturbance is important, and RIP may be a useful monitor of upper airway obstruction. In the present case, RIP and pulse oximetry were used to evaluate the adequacy of upper airway patency and oxygenation during the perioperative period.

\section{References}

1 France $N K$. Intubation of the nonvisualized larynx. In: Gregory GA (Ed.). Pediatric Anesthesia, New York: Churchill Livingstonc Inc., 1983: 826-7.

2 Goldenhar $M$. Associations malformations de l'œil et de l'oreille, en particulier le syndrome dermoide epibulbaire-appendices auricularies-fistula auris comgenita et ses relations avec la dysostose mandibulo-faciale. J Genct Hum 1952; 1: 243-86.

3 Gorlin RJ, Jue KL, Jacobsen U, Goldschmidt E. Oculoauriculovertcbral dysplasia. J Pcdiatr 1963; 63: 991-9.

4 Greenwood RD, Rosenthal A, Sommer A, Wolff G. Craenen J. Cardiovascular malformations in oculoauriculovertebral dysplasia (Goldenhar syndrome). J Pediatr 1974; 85: 816-8.

5 Scholtes $I L$, Veyckemans $F$, Obbergh $L V$, Verellen $G$, Gribomont $B F$. Nconatal anacsthetic management of a patient with Goldenhar's syndrome with hydrocephalus. Anaesth Intensive Carc 1987; 15: 338-40.

6 Rivlin J, Hoffstein V, Kalbfleisch J, McNicholas W, Zamel $N$, Bryan $A C$. Upper airway morphology in patients with idiopathic obstructive sleep apnea. Am Rev Respir Dis 1984; 129: 355-60.

7 Conway WA, Bower GC, Barnes ME. Hypersomnolence and intermittent upper airway obstrution: occurrencc caused by micrognathia. JAMA $1977 ; 237: 2740-2$.

8 Orr WC, Martin RJ. Obstructive sleep apnea associated with tonsillar hypertrophy in adults. Arch Intern Med 1981; 141: 990-2.

9 Lopes JM, Tabachnik E, Muller NL, Levinson H, Brayan $A C$. Total airway resistance and respiratory muscle activity during slecp. J Appl Physiol 1983; 54: 773-7.

10 Hoffstein V, Zamel N, Phillipson EA. Lung volume dependence of pharyngeal cross-sectional area in patients with obstructive sleep apnea. Am Rev Respir Dis 1984; 130 : 175-8.
11 Tilkian AG, Guilleminault C, Schroeder JS, Lehrman $K L$, Simmons $F B$, Dement WC. Hemodynamics in sleepinduced apnea: studies during wakefulness and sleep. Ann Intern Med 1976; 85: 714-9.

12 Bradley $T D$, Rutherford $R$, Grossman RF et al. Role of daytime hypoxemia in the pathogenesis of right heart failure in the obstructive slecp apnea syndrome. Am Rev Respir Dis 1985; 131: 835-9.

13 Nishino $T$, Honda $Y$, Kohchi $T$, Shirahata $M$, Yonezawa $T$. Effects of increasing depth of anaesthesia on phrenic nerve and hypoglossal nerve activity during the swallowing reflex in cats. Br J Anacsth 1985; 57: 208-13.

14 Nishino $T$, Takizawa K, Yokokawa N, Hiraga K. Depression of the swallowing reflex during sedation and/or relative analgesia produced by inhalation of $50 \%$ nitrous oxide in oxygen. Ancsthesiology 1987; 67: 995-8.

15 Nishino T, Kohchi T, Yonezawa T, Honda Y. Responses of recurrent laryngeal, hypoglossal, and phrenic nerves to increasing depths of anesthesia with halothane or enflurane in vagotomized cats. Ancsthesiology 1985; 63: 404-9.

16 Bonora M. John WMS, Bledsoe TA. Differential elevation by protriptyline and depression by diazepam of upper airway respiratory motor activity. Am Rev Respir Dis 1985; 131: 41-5.

17 Duffry $P$, Spriet L, Bryan MH, Bryan AC. Respiratory induction plethysmography (Respitrace ${ }^{\text {(tide) }}$ ): an evaluation of its use in the infant. Am Rev Respir Dis 1981; 123: 542-6.

18 Stagg D, Goldman M, Davis JN. Computer-aided measurement of breath volume and time components using magnetometers. J Appl Physiol 1978; 44(4): 623-33.

19 Millman RP. Fishman AP. Slcep apnea syndromes. In: Fishman AP (Ed.). Pulmonary Diseases and Disorders, 2nd ed., New York: McGraw-Hill, 1988: 1347-62. 